\title{
The effects of gas flow rate and annealing on the morphological properties of zinc oxide nanostructures thin film using chemical vapour deposition process
}

\author{
W.H. Khoo a, b, S.M. Sultan a, b, *, M.Z. Sahdan ${ }^{c}$ \\ a Computational Nanoelectronics Research Group (CONE), Universiti Teknologi Malaysia, 81310 UTM Johor Bahru, Johor, Malaysia \\ b Faculty of Electrical Engineering, Universiti Teknologi Malaysia, 81310 UTM Johor Bahru, Johor, Malaysia \\ c Microelectronics and Nanotechnology Shamsuddin Research Center (MiNT-SRC), Universiti Tun Hussein Onn Malaysia, 86400 Parit Raja, Batu \\ Pahat, Johor, Malaysia \\ * Corresponding author: suhanasultan@utm.my
}

\section{Article history}

Received 25 May 2016

Accepted 20 December 2016

Graphical abstract

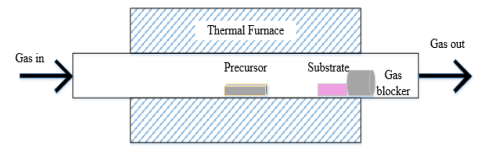

\begin{abstract}
Zinc Oxide nanostructures thin films have been deposited on glass substrates by using chemical vapour deposition technique at $1000^{\circ} \mathrm{C}$ assisted by gas blocker. Glass substrates was sputtered by $\sim 5 \mathrm{~nm}$ of gold to form a catalyst layer on top of glass. Different gas flow rates of $0.05,0.10,0.20,0.40$ $\mathrm{L} / \mathrm{min}$ were used in the deposition. After the deposition, the layer was annealed at temperatures of $500^{\circ} \mathrm{C}$ for 1 hours under atmospheric pressure. The surface morphologies of $\mathrm{ZnO}$ thin film were investigated field emission scanning electron microscope (FESEM). X-ray diffraction (XRD) results confirm the presence of $\mathrm{ZnO}$ layer with high peak of (002) crystal orientation and shows improvement after annealing. The mechanism of $\mathrm{ZnO}$ nanostructures formation will be discussed in this paper.
\end{abstract}

Keywords: $\mathrm{ZnO}$ nanostructures, Chemical vapour deposition (CVD), Gas flow rate, Annealing

\section{INTRODUCTION}

Zinc Oxide $(\mathrm{ZnO})$ is n-type group II-VI semiconductor crystallize in either cubic zinc-blende or hexagonal wurtzite structure where each anion is surrounded by four cations at the corners of a tetrahedron, and vice versa [1]. In addition, $\mathrm{ZnO}$ is a direct wide band-gap (3.37 eV) semiconductor with a large exciton binding energy $(60 \mathrm{meV})$ and high thermal stability, making it an important semiconductor with wide applications in optoelectronics [2], solar cell [3], piezoelectric device [4] and gas sensing [5,6]. ZnO thin films can be prepared by using various methods including physical deposition or wet process. Some of the methods reported are sol-gel[7,8], pulsed-laser deposition $[9,10]$, sputtering [11,12], spray pyrolysis, molecular beam deposition and chemical vapour deposition [13-15].

Chemical vapour deposition (CVD) is very attractive as a simple cost-effective means of preparing $\mathrm{ZnO}$ nanostructure. It is known that the growth of $\mathrm{ZnO}$ nanowires via CVD is sensitive to process conditions. Subtle changes in experimental conditions, such as source temperature, the distance between substrate and source, gas flow rate, substrate material, and choice of catalyst, can cause dramatic changes in the shape, density and size of the grown nanostructures. Therefore, it is important to investigate the parameters controlling the nanowires growth and the effect of these parameters on the $\mathrm{ZnO}$ nanowire structures. In this paper, we focus on the oxygen gas flow and the effect of annealing.

\section{EXPERIMENTAL}

Figure 1 shows the thermal CVD system which consists of the thermal furnace, a gas blocker, Argon and Oxygen gas flow, alumina boat used to put precursor and alumina tube. Figure 2 shows the process flow of the fabrication process of $\mathrm{ZnO}$ thin film nanostructures. It starts with preparation of $2 \mathrm{~cm} \times 2 \mathrm{~cm}$ glass substrate. The substrate was cleaned with acetone and ethanol using ultrasonic machine respectively for 10 minutes, then cleaned with deionized water and dried with nitrogen gas. About $5 \mathrm{~nm}$ of gold was coated on the cleaned glass.

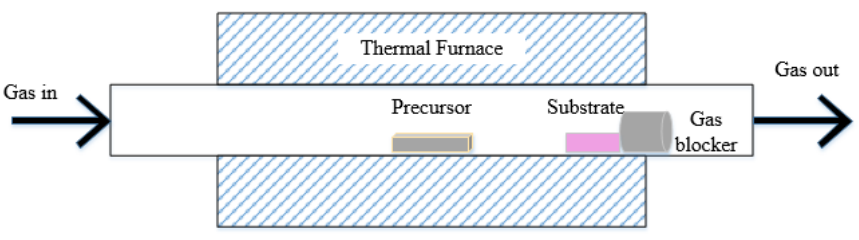

Fig. 1 The schematic diagram of thermal CVD system.

The sample was put inside the CVD chamber under low pressure and temperature for $\mathrm{ZnO}$ nanostructure thin film deposition. After deposition, the samples were characterized in XRD to confirm the presence of zinc oxide peaks. The morphologies of thin film was observed using field emission scanning electron microscopy (FESEM). 
The whole process was repeated and optimized until $\mathrm{ZnO}$ nanostructures was deposited on glass substrate. The sample was then annealed at $500{ }^{\circ} \mathrm{C}$ in atmospheric environment for 1 hour. Figure 3 shows the processes involved against time during the CVD deposition. Initially, the furnace was kept at $27^{\circ} \mathrm{C}$ and $0.21 /$ min of $\mathrm{Ar}$ gas flow was introduced for $10 \mathrm{~min}$. Then, furnace temperature was ramped up at $20^{\circ} \mathrm{C}$ per minute until a maximum temperature of $1000^{\circ} \mathrm{C}$ was reached. The furnace was kept at $1000^{\circ} \mathrm{C}$ for 1 hour. During this time, the oxygen gas was fed in. Next, the chamber was cooled down to $100^{\circ} \mathrm{C}$.

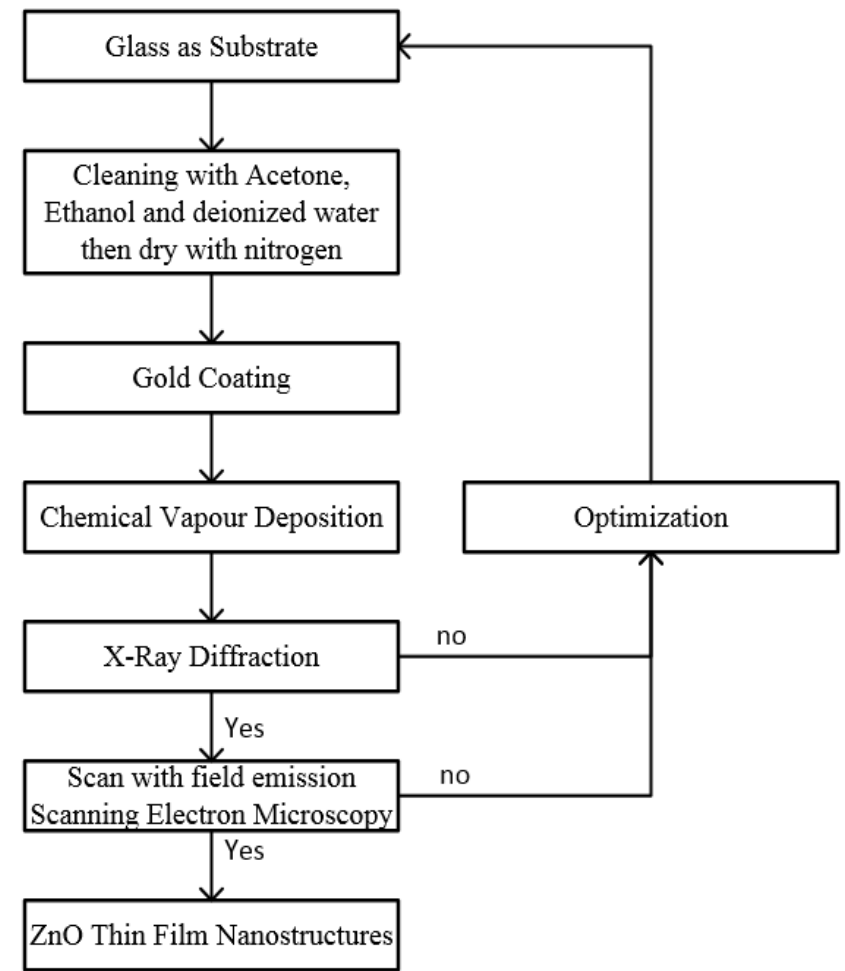

Fig.2 Fabrication Process flow.

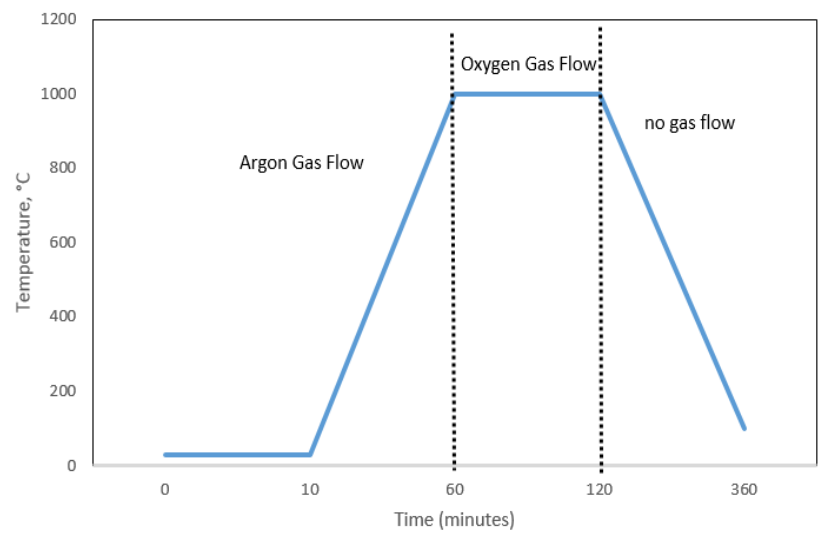

Fig. 3 Temperature versus time graph during CVD process.

\section{RESULTS AND DISCUSSION}

Figure 4(a) shows the scanning electron image of amorphous $\mathrm{ZnO}$ nanostructure with oxygen gas flow of $0.05 \mathrm{l} / \mathrm{min}$. The average grain size increases when oxygen gas flow increased to $0.41 / \mathrm{min}$ as shown in Figure 4(b).

Figure 5 shows the XRD pattern of $\mathrm{ZnO}$ thin film with different oxygen gas flow rate. From the spectrum, the main crystal orientation of $\mathrm{ZnO}$ thin film is along ( $\left(\begin{array}{lll}0 & 0 & 2\end{array}\right)$ and $\left(\begin{array}{lll}1 & 0 & 1\end{array}\right)$ at $34.37^{\circ}$ and $36.36^{\circ}$ respectively. Other orientations corresponding to $\left(\begin{array}{lll}1 & 0 & 0\end{array}\right)$ are present at $31.7^{\circ}$. The crystallinity improvement for all orientations is observed after annealing process. This is shown by the increment of full width at half maximum (FWHM) value. From the parameters obtained, the grain size of $\mathrm{ZnO}$ could be estimated using Scherer's formula as shows in equation [16]:

$$
D=\frac{0.9 \lambda}{B \operatorname{Cos} \theta}
$$

where $\mathrm{D}$ is grain size, $\lambda$ is X-ray wavelength of $1.54 \AA$, B is FWHM of the $\mathrm{XRD}$ peaks in radian and $\theta$ is diffraction angle.

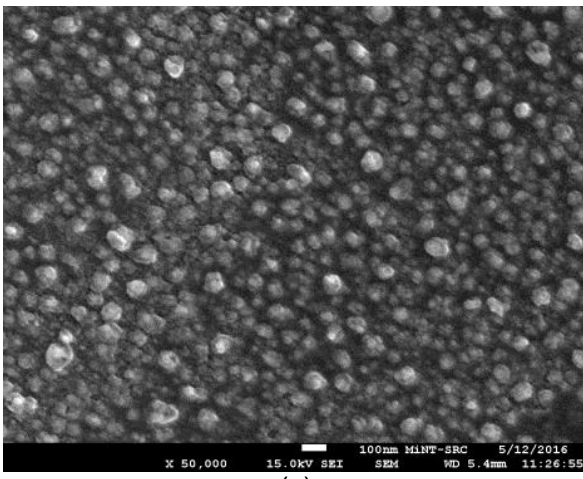

(a)

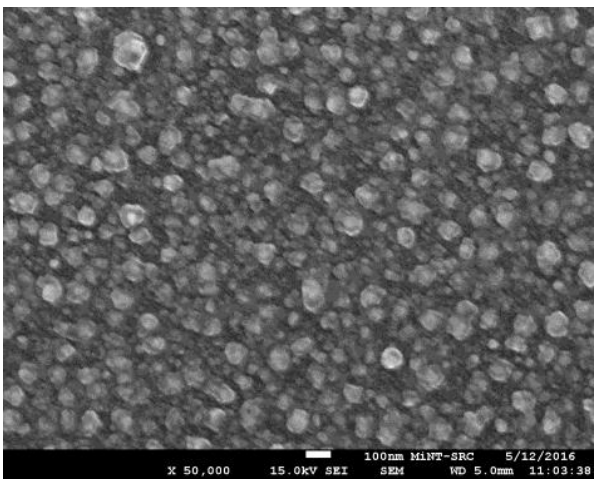

(b)

Fig 4 SEM image of $\mathrm{ZnO}$ nanostructure with oxygen gas flow of (a) 0.05 $\mathrm{l} / \mathrm{min}$. (b) $0.40 \mathrm{l} / \mathrm{min}$.

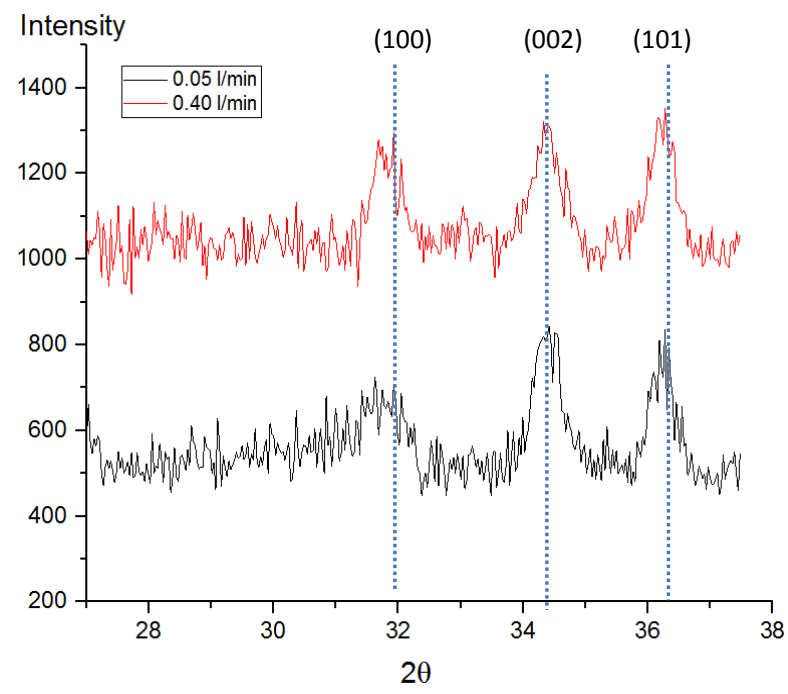

Fig. 5 XRD patterns of $\mathrm{ZnO}$ thin film with different oxygen gas flow.

Table 1 and Table 2 show the FWHM and grain sizes obtained before and after annealing for oxygen gas flow of $0.05 \mathrm{l} / \mathrm{min}$ and 0.40 $1 / \mathrm{min}$, respectively. For $0.05 \mathrm{l} / \mathrm{min}$, the calculated grain size increases from $13.2 \mathrm{~nm}$ to $19.8 \mathrm{~nm}$ for ( 100 ) orientation, $22.9 \mathrm{~nm}$ to $26.9 \mathrm{~nm}$ for $\left(\begin{array}{lll}0 & 0 & 2\end{array}\right)$ orientation and highest increment for $\left(\begin{array}{lll}1 & 0 & 1\end{array}\right)$ orientation which increased by $12.5 \mathrm{~nm}$ after annealing process This increment might due 
to the merging activity of the $\mathrm{ZnO}$ particles to form denser film after annealing with high temperature [17]. Meanwhile, the grain size and FWHM for $\mathrm{ZnO}$ thin film with oxygen flow rate of $0.401 / \mathrm{min}$ decreases after annealed. This might due to the presence of more oxygen atom surrounding $\mathrm{Zn}$ ion to form a weak and unstable bond when oxygen flow rate increases. After annealing, both $\mathrm{ZnO}$ thin films deposited with different flow rate shows almost similar FWHM and grains size. This shows that the weak and unstable bond could be easily broken during annealing and atom is rearranged themselves to form a stable $\mathrm{Zn}-\mathrm{O}$ compound.

Table $1 \mathrm{FWHM}$ and grain size before and annealing for $\mathrm{ZnO}$ thin film deposited at $\mathrm{O}_{2}$ gas flow of $0.05 \mathrm{l} / \mathrm{min}$

\begin{tabular}{|c|c|c|c|c|}
\hline Lattice & \multicolumn{2}{|c|}{ Before annealing } & \multicolumn{2}{|c|}{ After annealing } \\
\hline$(\mathrm{h} \mathrm{k} \mathrm{l)}$ & FWHM & Grain size (nm) & FWHM & Grain size (nm) \\
\hline 100 & 0.71 & 13.20 & 0.47 & 19.89 \\
\hline 002 & 0.41 & 22.96 & 0.35 & 26.90 \\
\hline 101 & 0.47 & 20.13 & 0.30 & 32.68 \\
\hline
\end{tabular}

Table 2 FWHM and grain size before and annealing for $\mathrm{ZnO}$ thin film deposited at $\mathrm{O}_{2}$ gas flow of $0.4 \mathrm{l} / \mathrm{min}$

\begin{tabular}{|c|c|c|c|c|}
\hline Lattice & \multicolumn{2}{|c|}{ Before annealing } & \multicolumn{2}{|c|}{ After annealing } \\
\hline$(\mathrm{h} \mathrm{k} \mathrm{l)}$ & FWHM & Grain size $(\mathrm{nm})$ & FWHM & Grain size $(\mathrm{nm})$ \\
\hline 100 & 0.30 & 32.30 & 0.59 & 15.86 \\
\hline 002 & 0.24 & 41.20 & 0.35 & 26.90 \\
\hline 101 & 0.35 & 27.00 & 0.35 & 27.03 \\
\hline
\end{tabular}

\section{CONCLUSION}

Zinc oxide thin film nanostructure was successfully fabricated by thermal chemical vapour deposition. The grain size of the nanostructure during $0.05 \mathrm{l} / \mathrm{min}$ of oxygen flow shows smaller grain size compared to film deposited at $0.4 \mathrm{l} / \mathrm{min}$. For $0.05 \mathrm{l} / \mathrm{min}$, the grain sizes increases after annealing. However, for $0.4 \mathrm{l} / \mathrm{min}$, the grain sizes reduce due to many dangling bonds present on the film before the annealing process. Therefore, FWHM from the XRD peaks and grain sizes changes after anneal due to atoms rearranging themselves into stable form.

\section{ACKNOWLEDGEMENT}

This work was supported by Ministry of Education Malaysia through Fundamental Research Grant Scheme (FRGS) vot 4F482. The authors would like to acknowledge the fabrication and experimental support from MiNT-SRC, Universiti Tun Hussein Onn Malaysia. The authors also acknowledge the support from UTM Research Management Centre.

\section{REFERENCES}

[1] A. K-Radzimska, T. Jesionowski, Materials 7 (2014) 2833-2881.

[2] H. Wan, H.E. Ruda, J. Mater. Sci.: Mater. Electron 21 (2010) 1014-1019.

[3] T. Yang, W. Cai, D. Qin, E. Wang, L. Lan, X. Gong, J. Peng, and Y. Cao., J. Phys. Chem. C 114 (2010) 6849-6853.

[4] V.S. Nguyen, D. Rouxel, B. Vincent, L. Badie, F.D.D. Santos, E. Lamouroux, and Y. Fort, Appl. Surf. Sci. 279 (2013) 204-211.

[5] J. Zhao, S. Wu, J. Liu, H. Liu, S. Gong, and D. Zhou, Sensor Actuat. B: Chem. 145 (2010) 788-793.

[6] H.D. Setiabudi, A.A. Jalil, S. Triwahyono, N.H.N. Kamarudin, R.R. Mukti, Appl. Catal. A: Gen. 417-418 (2012) 190-199.

[7] K. Ebitani, J. Konishi, H. Hattori, J. Catal. 130 (1991) 257-267.

[8] T. Shishido, H. Hattori, Appl. Catal. A: Gen. 146 (1996) 157-164.

[9] S. Triwahyono, T. Yamada, H. Hattori, Catal. Lett. 85 (2003) 109-115.

[10] S. Triwahyono, Z. Abdullah, A.A. Jalil, J. Nat. Gas Chem. 15 (2006) $247-$ 252.
[11] S. Triwahyono, T. Yamada, H. Hattori, Appl. Catal. A: Gen. 242 (2003) 101-109.

[12] N.N. Ruslan, N.A. Fadzlillah, A.H. Karim, A.A. Jalil, S. Triwahyono, Appl. Catal. A: Gen. 406 (2011) 102-112.

[13] W.C. Conner, J.L. Falconer, Chem. Rev. 95 (1995) 759-788.

[14] O.B. Yang, S.I. Woo, in: L. Guczi, F. Solymosi, P. Tetenyi (Eds.), New Frontiers in Catalysis, Proc. 10th Int. Cong. Catal., Budapest, Hungary, 19-24 July 1992, Elsevier Science Publishers B.V., Amsterdam, 1993, p. 671-680.

[15] A.K. Aboul-Gheit, A.E. Awadallah, N.A.K. Aboul-Gheit, E.S.A Solyman, M.A. Abdel-Aaty, Appl. Catal. A: Gen. 334 (2008) 304-310.

[16] A. Jentys, R.R. Mukti, H. Tanaka, J.A. Lercher, Microporous Mesoporous Mater. 90 (2006) 284-292.

[17] M.A.A. Aziz, N.H.N. Kamarudin, H.D. Setiabudi, H. Hamdan, A.A. Jalil, S. Triwahyono, J. Nat. Gas Chem. 21 (2012) 29-36. 